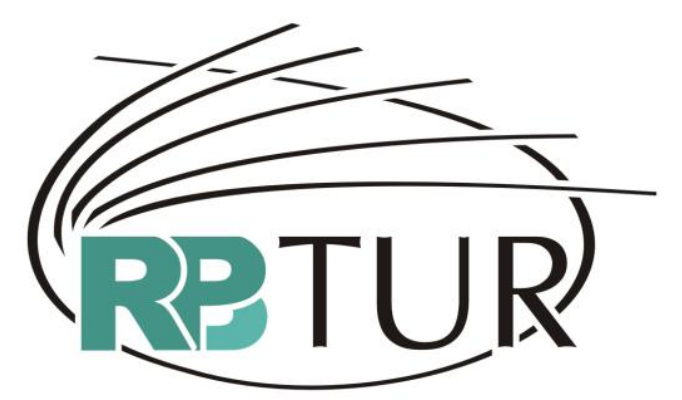

REVISTA BRASILEIRA DE PESQUISA EM TURISMO

\title{
RELATO DO I SEMINÁRIO INTERNACIONAL DE ESTUDOS CRÍTICOS EM TURISMO, NATAL/RN (BRASIL)
}

\section{REPORT ON THE $1^{\text {ST }}$ INTERNATIONAL CONFERENCE ON TOURISM CRITICAL STUDIES, NATAL (RIO GRANDE DO NORTE STATE, BRAZIL)}

\section{RELATO DEL I SEMINARIO INTERNACIONAL DE ESTUDIOS CRÍTICOS DE TURISMO, NATAL (ESTADO DE RIO GRANDE DO NORTE, BRASIL)}

Sérgio Rodrigues Leal ${ }^{1}$

Nos dias 24 e 25 de março de 2011, aconteceu, na Universidade Federal do Rio Grande do Norte, em Natal, o I Seminário Internacional de Estudos Críticos em Turismo, que contou com o patrocínio da Coordenação de Aperfeiçoamento de Pessoal de Nível Superior - CAPES. O evento, uma realização do Grupo de Pesquisas em Estudos Críticos em Turismo ESCRITUR, do Programa de Pós-Graduação em Turismo - PPGTUR, contou com a presença de renomados pesquisadores do Brasil e do exterior.

Com mais de 100 participantes de seis diferentes estados brasileiros, o Seminário foi dividido em quatro momentos - três mesas redondas e uma reunião do ESCRITUR, aberta a todos os presentes, como ouvintes, e aos professores pesquisadores, que puderam compartilhar suas experiências.

Coordenada pelo Prof. Dr. Sérgio Leal, líder do Grupo de Pesquisa, a primeira mesa redonda do dia, intitulada "Demarcando fronteiras do 
conhecimento em turismo: já temos um arcabouço conceitual próprio e genuíno?", contou com a Profa. Dra. Irena Ateljevic (Universidade Wageningen, na Holanda) e com o Prof. Dr. Marcelino Castillo Nechar (Universidade Autônoma do Estado do México). A Profa. Ateljevic destacou o cenário mundial atual, com o materialismo e o consumismo acima do bem estar do planeta, e apresentou o turismo transmoderno como uma alternativa para mudança. Segundo a palestrante, a abordagem transmoderna é uma mensagem de esperança, onde as mudanças necessárias para a salvação do planeta estão ligadas aos comportamentos de todos os seres humanos, inclusive aqueles que se encontram em viagem. Destacou, ainda, a necessidade de uma atenção da academia para a formação de profissionais e para a pesquisa com esta abordagem. O Prof. Nechar, por sua vez, defendeu a idéia de que vivemos um momento onde a produção crítica de conhecimento em turismo faz-se necessária. O caminho sugerido pelo Prof. Nechar é o da epistemologia, pois, na sua visão, construir conhecimento em turismo é algo crítico, filosófico. A repetição dos conceitos já estabelecidos, por si só, não favorece o avanço do conhecimento em turismo, havendo uma necessidade de novas abordagens. Ele encerrou sua fala fazendo uma bela analogia entre produzir o conhecimento em turismo e amar: assim como não há regras para como se deve amar, não há regras para como se produzir o conhecimento em turismo. O desenvolvimento e o avanço só virão com a inovação conceitual e metodológica.

A segunda mesa redonda do primeiro dia de evento foi intitulada "Panorama da educação e da pesquisa em turismo no Brasil" e foi coordenada pela Profa. Dra. Kerlei Sonaglio, professora do PPGTUR. Participaram do debate a Profa. Dra. Mirian Rejowski (Universidade Anhembi Morumbi) e o Prof. Dr. Luiz Gonzaga Godoi Trigo (Universidade de São Paulo). A Profa. Rejowski apresentou o cenário da educação e da pesquisa em turismo no nível da pósgraduação no Brasil, com ênfase nos programas específicos de turismo e nas teses de doutorados relacionadas ao tema defendidas entre 1990 e 2005, respectivamente. Apresentou, também, experiências internacionais na busca 
por uma nova visão para a produção do conhecimento em turismo. Por fim, após uma breve análise dos periódicos eletrônicos na área, teceu comentários sobre alguns pontos que considera relevantes para o avanço do turismo na academia, tais como a necessidade de se colocar a ética, a sustentabilidade e a hospitalidade no dia-a-dia dos acadêmicos; a dificuldade para se publicar em periódicos estrangeiros, devido ao baixo nível de proficiência em inglês; a pouca integração entre os pesquisadores ibero-americanos, e de países de língua portuguesa; entre outros. Já o Prof. Trigo, abordou, de forma descontraída, as tendências do setor e a necessidade de formação e qualificação para melhor atender a crescente demanda turística mundial. Tratou, também, da questão da competitividade no setor turístico e da necessidade de adequação às tendências mundiais, detalhando os doze pilares da competitividade econômica apresentados pelo Fórum Econômico Mundial. Fez menção, ainda, às pesquisas exitosas na última edição do Prêmio EBAP/FGV e às instituições com Programas de Pós-Graduação em Turismo ou afins no país.

No segundo dia do evento, foi realizada a última mesa redonda do Seminário bem como a reunião do ESCRITUR. A mesa redonda intitulada "Demarcando fronteiras científicas para os estudos em turismo: abordagens e correntes teóricas: o que há de novo sob o sol?" foi coordenada pela Profa. Dra. Rosana Mazaro, Coordenadora do PPGTUR, e teve a participação dos Professores Doutores Alexandre Panosso Netto (Universidade de São Paulo), e Carlos Costa (Universidade de Aveiro, Portugal). O Prof. Panosso baseou sua apresentação na atual crise da educação. Para ele, há uma crise de conhecimento, pois falta conhecimento das teorias filosóficas de pensamento. Assim, falta teorização, pensamento crítico, pensamento profundo, pensamento coerente, ou seja, falta pensamento lógico. Fez críticas, ainda, à falta de valores culturais, humanos, morais e éticos bem como de valores históricos. Ao apresentar caminhos alternativos, o Prof. Panosso focou sua abordagem na epistemologia como forma de alavancar o conhecimento na área, caso contrário continuaremos com a atual banalização da teoria. Quanto 
à falta de valores históricos, o Prof. Panosso ressaltou a importância de se buscar os textos originais que embasam o conhecimento acadêmico do turismo no mundo. Entre os possíveis caminhos propostos para o enfrentamento da crise encontram-se: a união entre pesquisadores; uma maior atenção aos países onde o inglês não é o idioma oficial; o fortalecimento da epistemologia do turismo; a busca pela construção da teoria crítica; a ampliação dos fundamentos e dos conhecimentos teóricos da e na filosofia; entre outros. Dando continuação ao debate proposto na mesa redonda, o Prof. Carlos Costa teve a palavra. A sua visão foi diferente daquela apresentada pelos demais convidados, pois assumiu e defendeu, com embasamento teórico e prático, a linha positivista de pensamento. Vale ressaltar que, embora embasado em outra linha de pensamento, reconheceu alguns dos mesmos problemas apresentados pelos seus colegas e, também, propôs alternativas para superálos. A sua apresentação foi estruturada da seguinte forma: novas dinâmicas no setor do turismo; novas dinâmicas na pesquisa em turismo; e evolução da produção científica em Portugal. A parte inicial focou, especialmente, na economia de experiências e na sua aplicação no turismo. Para ele, os destinos precisam estar atentos às questões relacionadas a diferenciação, inovação, competitividade, e investigação e desenvolvimento para que consigam sobreviver no cenário atual do setor turístico. Quanto à pesquisa em turismo, focou na qualidade (originalidade, rigor e contribuição para o conhecimento) e na agenda para pesquisas na área. Ressaltou, ainda, a necessidade de adequação dos cursos de turismo para esta nova realidade do setor e da pesquisa. Por fim, apresentou dados estatísticos referentes à produção científica portuguesa em turismo, sempre fazendo menção à academia brasileira.

O evento foi encerrado com a reunião do ESCRITUR. Este foi um momento importante, já que tanto os pesquisadores que fazem parte do Grupo como todos os outros presentes puderam expor suas idéias para o fortalecimento da pesquisa em estudos críticos em turismo. Propostas de trabalhos conjuntos nasceram naturalmente e a colaboração entre 
ISSN: 1982-6125

pesquisadores de diferentes estados brasileiros e de diferentes países foi encorajada. Espera-se que o Seminário torne-se um fórum permanente de discussão entre pesquisadores preocupados com o conhecimento crítico em turismo.

Relato recebido em abril de 2011.

Aprovado para publicação em abril de 2011. 